\title{
Mathematical Modelling of the Relationship between Two Different Temperament Classifications: During the Covid-19 Pandemic
}

\author{
Mohammed Aref Abdul Rasheed ${ }^{1}$, Murtaza M. Junaid Farooque ${ }^{1 *}$, \\ Haridas S. Acharya ${ }^{2}$, Mohammed Sharique A. Quadri ${ }^{3}$ \\ ${ }^{1}$ Assistant Professor,Department of MIS, Dhofar University, Salalah, 211, Sultanate of Oman, Muscat, Oman \\ ${ }^{2}$ Professor, Allana Institute of Management Sciences,411001, Pune, India \\ ${ }^{3}$ Assistant Professor, College of Medicine, Almaarefa University, 11597, Riyadh, Kingdom of Saudi Arabia
}

\begin{abstract}
In medicine, it is well known that healthy individuals have different physical and mental characteristics. Ancient Indian medicine, Ayurveda and the Persian-Arabic traditional Unani medicine has two distinct approaches for the classification of human subjects according to their temperaments. The individual temperament is an important foundation for personalized medicine, which can help in the prevention and treatment of many diseases including COVID-19. This paper attempts to explore the relationship of the utmost important concepts of these systems called individual temperament named as Prakruti in Ayurveda and Mizaj in Unani practice using mathematical modelling. The results of mathematical modelling can be adopted expediently for the development of algorithms that can be applied in medical informatics. For this, a significant literature review has been carried out. Based on the previous researchers' reviews the essential parameters have been identified for making the relationship and hypothesis were framed. The mathematical modelling was adopted to propose the existence of the relationship between the parameters of such an ancient and rich medicine systems. The hypotheses are validated through the mathematic driven model.
\end{abstract}

\section{Keywords:}

Temperament; Medical Informatics;

Alternative Medicine;

Unani Mizaj; Ayurvedic Prakruti;

Prakriti; Ayurveda; Unani;

Individual Difference.

\section{Article History:}

Received: 16 November 2020

Revised: 21 December 2020

Accepted: 11 January 2021

Published: $01 \quad$ February 2021

\section{1- Introduction}

Health can be defined as a state of physical and mental well-being. An individual remains in this state, until it is affected by certain internal or external factors. The job of the physicians is to bring it back to state of health. Currently, conventional medicine is looking forward towards personalizing medicine and paying attention to individual differences in the pathogenesis, progression of diseases and response to therapeutics. There are various healthcare and medicine systems, prevalent in India, traditional as well as modern. Along with the modern medical system, there exist alternative medical systems like Ayurveda, Siddha, Unani Tibb, Yoga, Naturopathy, Amchi, etc.

Ayurveda and Unani Tibb are amongst very ancient practices. Although there are a few differences and there are many similarities between these two systems of health care. Ayurveda practices originated in ancient India, while Unani medical system originated in ancient Greece. The Unani medical system was later developed by Arabs, Persians, Turkish and it was furthered advanced in Indian sub-continents. Ayurveda is prevalent in India, and practiced countries like

\section{*CONTACT: Mfarooque@du.edu.om}

DOI: http://dx.doi.org/10.28991/esj-2021-01258

(C) 2021 by the authors. Licensee ESJ, Italy. This is an open access article under the terms and conditions of the Creative Commons Attribution (CC-BY) license (https://creativecommons.org/licenses/by/4.0/). 
Nepal, Sri-Lanka, etc. It is also becoming popular in western countries including United States. Unani Tibbs is practiced mostly in India, Pakistan, Bangladesh, Iran, etc. It is also practiced in South Africa and United Kingdom.

There is a need of comparing this ancient wisdom of south Asia, to derive the best of both systems. However, there exist many barriers to this issue. Most of the research and authentic texts of Ayurveda are in Sanskrit or Hindi while for Unani, it is in Arabic, Persian or Urdu. A less amount of authentic literature is available in English. Many of times physician are not ready to cooperate with each other's. This integration and comparison will not only help in treatment and prevention of dieses but also promotion of healthy lifestyle.

In this paper, we have tried to compare and co-related one of important concept of these system called individual temperament, known as Prakruti/Prakriti in Ayurveda and Mizaj in Unani practice. We have used mathematical modelling to prove the existence of relationship between these twin temperaments. Although a lot of clinical trials and authenticated research will be required in future for validation of the concept. The outcome of this study could play an imperative role in providing support in bringing the concept into applied system using ICT. In addition, this paper can also contribute to the body of knowledge by acting as foundation stone in this step.

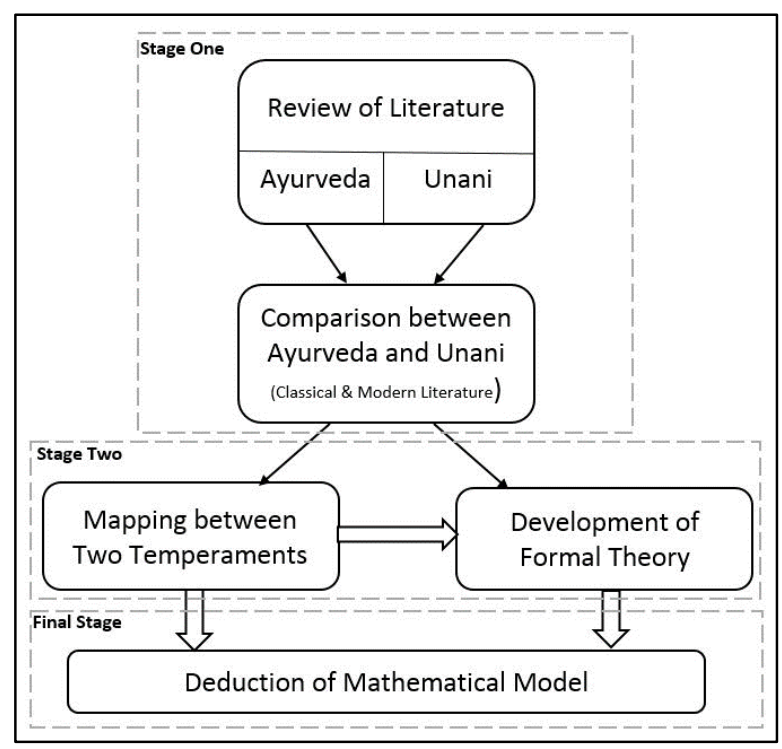

Figure 1. Three Stages Methodology (Flowchart)

\section{2- Literature Review}

The previous literatures have been reviewed in order to find out and compare the applications of temperaments studies in treatment and immunology, the historical and modern development in the field of Ayurveda as well Unani medicine.

\section{2-1- Ayurvedic Temperament (Prakruti)}

According to Ayurveda every individual as specific temperament (Prakruti/Prakriti), which can be understood as mind-body constitutions. This temperament is based on Dosha, which are Vata, Pitta and Kappa. The health of an individual is influenced by their innate proportion of these three Dosha and their current state of balance or Vikruti (disequilibrium) [1]. Vata, Pitta and Kappa are the three Dosha assumed to be present in the human body, and their imbalance is the major cause of state of health. Treatments always aim at restoring the balance. The dominance of any Dosha in a person determines his or her Temperament, at the gross level [2]. The Doshas, continuously formed in the human body are responsible for the homeostasis and metabolic activities of an individual. The proportion of Doshas constituents is unique for every person and is termed as his/her Temperament. Temperament determines the physiological and psychological tendencies and influences their physiological features like the texture and color of the skin, hair, eyes, length of fingers, the shape of the palm, body frame, strength of digestion etc., and psychological features like their nature (introverted, extroverted, calm, excitable, intense, laid-back), including their reaction to stress. Generally, Temperament does not change throughout the lifetime of a person and can be used to access the patient's suitability for a treatment [3].

Dosha Prakruti can be determined scientifically using Physical, Physiological and Psychological Characters [4]. The Ayurvedic physician use various means for temperament assessment. This will include like physical examination, involving visual, tactile, olfactory, and auditory assessments; inference based on information collected, by indirect means including asking questions does the traditional method of Ayurvedic temperament determination and conclusions drawn based on available data, knowledge, and experience [5]. These methods can be broadly Touch based, Question based, or observation based [6]. 
For Temperament assessment Ayurveda practitioners sometime chooses a self-reported or structured interview constitutional questionnaire; however, is no standardized or validated self-reported constitutional questionnaire tool employed by physicians or institutions. There are a variety of questionnaires, publicly available, which are developed by either developed by researchers, educational institutions and Ayurveda products companies [7].

Different researchers have developed different questionnaire or observation tables based on ancient texts. Bell et al. used 10 question based on physiological or psychological characteristic e with 3 options representing each Dosha to select from [1]. Similarly, 31 physiological and psychological characteristics observed by Ayurvedic doctors can be found in Kshirsagar and Magno (2011) [8]. Usha and Vasant (2005), Prasher et al. (2008) developed a lengthy questionnaire with for clinical phenotyping was designed based on Ayurvedic literature on phenotypes and methods of Prakriti assessment [9-10]. Sixteen physical features were studied to assess Ayurvedic temperament according to the classical textual references in Ayurveda by Jyothy and Siddhali (2017) [11]. There have been several attempts at designing the reliable tools and protocols for assessment of temperament which each suffers from its own limitations [12].

\section{2-2- Unani Temperament (Mizaj)}

According to Unani postulates, there are four major fluids in a human body, i.e., four independent parameters which determine the health status of an individual. These are named Balgham (phlegm), dam (blood), Safra (yellow bile), and Sauda (black bile) respectively. When these fluids are present in the right proportion in the body, the body remains healthy. Based on dominance of anyone of the humors the Temperament of a person is determined [13]. The human temperaments corresponding to these fluids are, respectively, sanguine (Damvi), phlegmatic (Balghami), choleric (Safrawi) and melancholic (Saudawi). Each person is considered to have a specific humoral makeup, determined by the predominance of a given fluids in his or her constitution. The quality and quantity of the fluids in person's unique, determines and guarantee healthy conditions, while misbalance may result in ailment or disease [14]. Temperament (temperament) which is an important concept of Unani medicine, represents the metabolic constitution, psychological makeup and behavioral pattern of an individual [15].

Unani physicians have described several parameters for determination of Temperament. The most acceptable and appropriate determinants have been given by Ibn-e-Sina (980-1037 AD) in his famous book Al-Qanoon-fil-Tibb., he suggested 10 parameters for the assessment of Temperament such as physique, physiology, psychology, responsiveness of organs, etc. [16]. Hakim Sayed (1980) has developed a tool with 55 sub parameters of these from 10 classes [17]. Some other text has used around questionnaire with 20 sub parameters based on these 10-class developed from classical texts [18]. According to Akhtari (2018) there is absence of a homogenous method for evaluating temperament [19]. Most of the researcher in India use a standard questionnaire formulated by Central Council for Research in Unani Medicine (CCRUM), Ministry of AYUSH, New Delhi for assessment Temperament (temperament) of the subjects [18]. Mojahed et al. (2014) tried to study self-administered Temperament questionnaire for assessing its reliability and validity in Iran. The researchers found that most of the questionnaire based on classic literature's Temperament identification indices had satisfactory reliability. The authors suggested development of a brief self-report Temperament estimating [20].

Mozaffarpur et al. (2017) tried to investigate agreement between personal medicine experts in Temperament identification and to categorize the criteria used for Temperament identification. The researchers found that till that time there was no standard protocol for Temperament assessment. Each expert in their study participated in the project using their own method to determine Temperament. There researcher felt a strong need for increasing the agreement between experts in designing and validating standard scales for determination of Temperament [21]. Roshandel et al. (2016) tried to prepare a standard questionnaire on assessment of Temperament using classical texts in Greek, Arabic, and Persian. The questionnaire, however, need to be further tested and validated [22].

\section{2-3- Applications of Ayurvedic and Unani Temperaments in Treatment and Immunology}

Bhushan et al. (2005) found a co-relation between Dosha prakruti and genotypes, the researchers found observed a reasonable correlation between HLA type and Prakriti type [23]. Rotti et al. (2014) studied relationship between temperament and immunology, they found the exisance relationship between immune response and individual temperament, which is in conformity with textual references in Ayurveda [24]. Relationship of temperament and cancer has been studied by Venkataraghavan et al. (1987) [25]. Similarly, Joob and Viroj (2012) studied the relationship between Temperament and diabetes [26]. In the current period, the importance of Temperament in dealing with COVID 19 were studied by Nair et al. (2020), Kukade et al. (2020), Nema et al. (2020) [27-29].

Setooni et al. (2016) found that physical activity and sedentary behavior is affected by individual Unani Temperament [30]. Khan et al. (2020), studied the relationship of Temperament with immunity [31]. The relationship between cancer type and humoral temperament was studied by Carden and Judson (2008) [32]. IIkhani et al. (2019), 
Baig et al. (2018) studied relationship between Temperament and diabetes [33-34]. In the current epoch, the importance of Temperament in dealing with COVID 19 were studied by Nikhat and Fazil (2020), Khan et al. (2020) [35-36].

\section{2-4- Use of Modern Scientific Tools in Assessment of Ayurveda and Unani Temperaments}

Some researchers have used various modern scientific tools for automatic assessment and analysis of temperament like Pulse diagnosis [37-38]. Khajuria (2020) used the software to detect the body pain using classification prototype [39]. Wedaduru is Ayurveda based decision support system developed in Srilanka for disease screening and remedy analysis solution [40], similarly Ayusoft is a the Indian decision support system for Ayurveda, developed with a vision to convert classical Ayurvedic texts into comprehensive, authentic, intelligent and interactive knowledge repository with complex analytical tools. Prakriti assessment by Ayusoft works using weightage configuration [41, 5]. A mobile device application was designed to enables an Ayurvedic clinician to enter and share a patient's Dhosa by Stranieri et al. [42]. Machine learning technique was used for assessments of Ayurveda temperament types by Tiwari et al. (2017), Madaan et al. (2020), Farooque (2016) [43-45]. Similarly, researchers applied Neural networks [46], computer vision [3], using anthropometric parameter [47-49].

Some of the researchers have tried to relate scientifically Unani temperament with somatotypes [50-51]. Nasir (2019) used computerized image processing to the assess the color and shape of the individual's hair. The thickness of hair was measured by the Digital Vernier Caliper. This data was used in accessing Unani temperament [52]. Afrough and Forooque (2012) suggested integration of Unani temperament assessment tool with data mining capability in hospital management system [53]. A. Hamzeheian et.al (2019) constructed an ontology-based knowledge base of concepts of Temperament in the domain of Materia medica to help offer a shared and common understanding of this concept, enable reuse of the knowledge. It also provided indented tree view and an interactive graph view using WebOwl tool, to visualize the ontology [54]. Farooque et al. (2011) suggested Machine learning a decision tree approach for classification of human subjects according to Unani Temperament [55]. Bandgar et al. (2013) experimented with applying different data mining techniques on above data [56]. Roya et al. (2018) used fuzzy decision tree approach for data mining and modeling of the temperament diagnosis [57].

\section{2-5- Mapping of Ayurvedic and Unani Temperaments}

Mulla et al. (2014) compared the system using questionnaires [58]. Mulla et al. (2013) used artificial neural networks to get Unani Temperament from Ayurvedic Temperament and vise-versa. Some researchers both ancient and modern who have tried to solve the problem of mapping the two [59]. Rolfe (2002) has suggested in the relationship between three Ayurvedic Dosha and four Unani Temperament can be mapped. She presented Balgham and Sauda together, as kappa, dam is Vata, Safra as pitta [60]. Endo and Nakamura (1995) proposed that Blood i.e. Dam to be considered as the combinations of all other three Doshas [61]. Guha quoted Maharishi Sushruta, who has included blood or Dam or Shonit as the main constituent together along with other three Doshas [62].

There exist very few literatures comparing both the system, there is still a wide gap. There is a strong need to bridge this gap. Although from above literatures, we found that there is no consensus among the scholars regarding the mapping of these two temperaments. We proposed to use the mathematical modeling to deduce the relationship between these two temperaments of an individual.

\section{3- Theory of Equivalence of Two Classification Methods}

Let us consider there is a set $\mathrm{X}$ of $\mathrm{n}$ objects $X=\left\{x_{1}, x_{2}, x_{3} \ldots, x_{n}\right\}$.. There can be different methods of classification or grouping of these objects, let us consider that there are two methods i.e., $\mathrm{m} 1$ and $\mathrm{m} 2$. The first method ( $\mathrm{m} 1)$ classifies objects in three groups A, B, C, using attributes independently measured according to one method of 'information generation'.

Let us consider there is a set $X$ of $\mathrm{n}$ objects $X=\left\{x_{1}, x_{2}, x_{3} \ldots, x_{n}\right\}$. There can be different methods of classification or grouping of these objects, let us consider that there are two methods i.e., $m_{1}$ and $m_{1}$.

The first method $m_{1}$ classifies objects in three groups A, B, C, using attributes independently measured according to one method of 'information generation'. The second method $m_{2}$ classifies objects into four groups i.e. $P, Q, R, S$, using attributes independently measured according to second method of 'information generation'. However, the attributes talk about the same final 'information', which is the hidden real class of object so our fist axiom is that:

Real GroupID $=$ Unique Label $=f\{A, B, C, A B, A C, B C, \ldots \ldots \ldots . . . A B C\}$

Real GroupID $=$ Unique Label $=g\{P, Q, R, P Q, P R, R S, \ldots, P Q R, \ldots \ldots, P Q R S\}$

Mathematically speaking (equation 1) is a three-parameter system where as (Equation 2) is a four-parameter system. It is a well-known fact that in the presence of a relation of the type $S=S(P, Q, R)$, if it exists (Equation 2) would also reduce to a three-parameter system with a natural mapping between the two systems as: 
$P=\left(A w_{1}+B w_{2}+C w_{3}\right) \quad$ with $\quad \sum_{1}^{3} w_{i}=1$

In other words, each $\mathrm{P}, \mathrm{Q}, \mathrm{R}$, is a proper mix of $\mathrm{A}, \mathrm{B}, \mathrm{C}$ and $\mathrm{S}$ is a combination of $\mathrm{P}, \mathrm{Q}$, and $\mathrm{R}$, hence is indirectly dependent on A, B, C. Though (equation 3) projects the relationship as linear, in reality linearity is not mandatory.

What can be the relationship between ABC and PQRS?

- $\mathrm{A}=\mathrm{P}, \mathrm{B}=\mathrm{Q}, \mathrm{C}=\mathrm{R}$ and $\mathrm{S}=\mathrm{AB}$ and so on there will be infinitely many options.

- $\mathrm{A}=\mathrm{P}, \mathrm{B}=\mathrm{Q}, \mathrm{C}=\mathrm{R}, \mathrm{ABC}=\mathrm{S}$ can be an alternative

- $\mathrm{A}=\mathrm{PQR}, \mathrm{B}=\mathrm{QRS}, \mathrm{C}=\mathrm{PQRS}$

\section{4- Mathematical Deduction}

Ayurvedic and Unani Temperament are the two methods of classification human subjects according to their temperaments. Let us find mathematically deduce relationship between these two methods $\left(m_{1}\right.$ and $\left.m_{2}\right)$. According to the theory of Ayurveda every individual (I) has (Equation 3) Dosha i.e., Vata, Pitta, \& Kappa denoted by:

$I=\{\omega, \pi, k\}$

For every $I$ there is a unique combination of $\omega, \pi$ and $k$, every individual will have a degree of membership in all three Dosha and no Dosha is absent therefore we say that the degree of membership is fuzzy:

$(\omega)+(\pi)+(k)=1.0$

The Ayurvedic Temperament of an individual can be determined based on dominance of the Dosha. No two Dosha will be equal in any case. The most dominant Dosha will be the temperament of the individual. i.e., Ayurvedic temperament $(\pi \rho)$ can be determined as:

$\pi \rho=\max (\omega, \pi, k)$

$\omega, \pi$ and $\mathrm{k}$ can have any values between 0 and 1.0. Every individual $(I)$ has degree of membership of all three sets, i.e. $\omega, \pi \& \mathrm{k}$ the maximum belonging will be determined by maximum membership. If there is any change in the value of $\omega, \pi$ or $\mathrm{k}$ the temperament $\pi \rho$ is distort to $\pi \rho^{\prime}$, there is condition of instability and health is distorted and it should be brought back to the stable condition. Similarly, according to theory of Unani Tibb, every Individual $(I)$ has four fluids i.e. Balgham, Dam, Sauda, Safra denoted by:

$I=\{\beta, \delta, \sigma, \emptyset\}$

For every $I$ there is a unique combination of $, \delta, \sigma$ and $\emptyset$, every individual will have a degree of membership in all four fluids and no fluid is absent therefore we say that the degree of membership is fuzzy:

$(\beta)+(\delta)+(\sigma)+(\varnothing)=1.0$

The Unani Temperament of an individual can be determined based on dominance any one of these fluids i.e. Unani temperament. $\pi \mu$ can be determined as:

$\pi \mu=\max (\beta, \delta, \sigma, \emptyset)$

Every individual $I$ has degree of membership of all four sets, i.e. $\beta, \delta, \sigma$ and $\emptyset$ the maximum belonging determines the maximum membership. If there is change in value of any $\beta, \delta, \sigma$ and $\emptyset$ the temperament $\pi \mu$ is distorted to $\pi \mu$ '. It has to be brought again back to normal $\pi \mu$.

Relationship: as per the Equation 5 and 8, we can say that:

$(\omega)+(\pi)+(k)=(\beta)+(\delta)+(\sigma)+(\varnothing)$

When $\pi \rho$ changes to $\pi \rho^{\prime}$ and $\pi \mu$ changes to $\pi \mu^{\prime}$. Based on the above statement we framed the following hypotheses: H1: $(\beta, \delta, \sigma$ and $\emptyset)$ obtained by UNANI method of investigation can predict $(\omega, \pi, k)$ of Ayurvedic investigation. H2: $(\omega, \pi, k)$ obtained by AYURVEDIC method of investigation can predict $(\beta, \delta, \sigma$ and $\emptyset)$ of Unani investigation.

\section{5- Results and Discussion}

Let us summarize the research that have compared both methods. R. Rolfe (2002) has suggested in the relationship between ayurvedic Dosha and Unani humors/temperaments, which can mathematically state as follows [60]:

$\beta \rightarrow>, \delta \rightarrow \infty, \sigma->k, \emptyset->\pi$ 
It was proposed that Blood i.e., Dam $\delta$ was comprised of the properties of every humor without having its own peculiar properties [61]. Therefore, the diseases caused by deranged "blood" were regarded as an aggregate disease caused by the other three deranged humors. This is stated as follows:

$\delta=\varnothing(\omega, \pi, k)$

Guha of Banaras Hindu University stressed that $\beta, \sigma, \emptyset$ of Unani system can be compared with $\omega, \pi, k$ respectively. In Tridosha theory $\delta$ has not been included but Maharishi Sushruta has enumerated Shonit $(\delta)$ as the main constituent together with Tridosha [62]. This is stated as:

$\beta \rightarrow>, \quad \sigma->\pi, \emptyset \rightarrow>\omega$

Unani values for $\beta, \delta, \sigma, \emptyset$ and Ayurvedic values for $\omega, \pi, k$ the healthy individuals of both genders was obtained in an experiment by [59]. The ANN Model was developed using a data set of $73 \%$ of the records and was tested with $27 \%$ of the records. The weights of hidden layer were calculated using multiple regressions. We proposed a model of relationship based on the findings of [59], which is expressed:

Definition 1: $\mu(i, j)=\mu(j)=$ Unani Temperament(Mizaj) scores of individuals $j$, with $i=1,2,3,4$ corresponding to $\beta, \delta, \sigma$ and $\emptyset$ respectively. The $\mu$ is a vector of four components as indicated above.

Definition 2: $\rho(i, j)=\rho(j)=$ Ayurvedic Temperament (Prakruti) scores of individuals $j$, with $i=1,2,3$ corresponding to $\omega, \pi$ and $k$ respectively. The $\rho$ is a vector of three components as indicated above. We propose U2A Model which takes $\mu$ as input and gives $\rho$ as output with reasonable accuracy. i.e.;

$U 2 A(\mu)=\rho+e_{1}$

Similarly, the can we have a reverse model,

$U 2 A(\rho)=\mu+e_{2}$

Where $e_{1}$ and $e_{2}$ are a random error factor.

Naisal and Kumar (2016) has adopted Sostak Fuzzy Topology to mathematically represented the Ayurveda temperament [63], similarly Smarandache, (2018) adopted nuetropsychic logic to represent the Unani temperament [64], but none of the scholars of mathematics have compared both or tried to mutually convert from one system from another.

In the present study, the researchers have established that it is mathematically possible obtain Ayurvedic temperament of an individual, if the unani temperament is known and vice versa. As evident from the Equations 14 and 15 . Previous research although (Endo and Nakamura (1995), Rolfe (2002) Ahmed (2009) and Mulla et al. (2014), have compared both the system using various approached but they have not suggested any technique for mutual conversion. Mulla et al. (2014) has used ANN and fuzzy logic for mutual conversion, however strong theoretic base was missing, this gap is fulfilled by the current research.

\section{6- Conclusion}

The Present research is multi-disciplinary in method, where two different ancient medical systems are equated using mathematical approach, which can be used in development of Information system. Traditional and alternative medicine give more Importance to individual difference while treating a person. This evident from the methodology adopted in Ayurveda and Unani medical approaches. The Ayurvedic temperament, which is three-parameter system, while Unani temperament e is a four-parameter system. Both of this system represent same truth in different perspective. Hence, it can be believed that there must be some relationship between these two representations. It should be possible to obtain value of one from another. To establish any fact or concept it should be first established using formal theory and later empirically validated. In order to establish the formal theory, mathematical modelling was to obtain Ayurvedic temperament from Unani (A2U) and Unani temperament from Ayurveda (U2A). The result indicates, it is mathematical possible to obtained one from another with some amount of error, if this error is minor, then it is a great achievement. However, there is a need lot of trials, experimentations, and validating the concept with actual data. If it is successful then it can give benefit of both systems, especially in case dealing with those medical and health issue which stressed more on the individual differences and personalized medicine including COVID-19 etc. Once it is established and empirically validated, it can be used in development of health care information system. This information system would be a blend of modern medicine, backed back by ancient wisdom of health and immunity, implemented using neural network, fuzzy logic, deep learning, machine learning etc. algorithm with robust Information Technology infrastructure.

\section{7- Declarations}

\section{7-1-Author Contributions}

The article is joint interdisciplinary contribution of four different authors, the first author M.A.A.R. made the study conception and design, second and corresponding Author M.M.J.F. has done review of the literature for the research. 
The Third Author H.S.A., who is from area of mathematics validated, and improved the developed mathematical model. The fourth author M.S.A.Q. is from the field of medical science. He reviewed and validated the paper from medical science perspective. All authors reviewed the results and approved the final version of the manuscript.

\section{7-2-Data Availability Statement}

No new data were created or analyzed in this study. Data sharing is not applicable to this article.

\section{7-3- Funding}

The author(s) received no financial support for the research, authorship, and/or publication of this article.

\section{7-4-Acknowledgements}

The authors would like to acknowledge the researcher G. Mulla, M. J. M. Farooque and H. S. Acharya, for providing us the data of ANN model. The authors would also acknowledge Dhofar University Oman, Pune University India, Almaarefa University KSA.

\section{7-5- Conflicts of Interest}

The author declares that there is no conflict of interests regarding the publication of this manuscript. In addition, the ethical issues, including plagiarism, informed consent, misconduct, data fabrication and/or falsification, double publication and/or submission, and redundancies have been completely observed by the authors.

\section{8- References}

[1] Bell, Clayton, R. Eric Heidel, Jean Sunega, and Jeanne Drisko. "Ancient Wisdom: Can Ayurvedic Prakruti Provide Invaluable Insights into Integrative Medicine?." Ayu. J Health 15, no. 3 (2017): 27-34.

[2] Svoboda, R. E. “Prakriti: Your Ayurvedic Constitution” Lotus Press, (1998): 224.

[3] Gadre, Gayatri. "Classification of Humans into Ayurvedic Prakruti Types Using Computer Vision" (2019):710. doi:10.31979/etd.dmwg-2nee.

[4] Buchiramulu, Rapolu Sunil, and Piyush Tripathi. "Assessment of Prakriti to maintain the health condition and for the prevention of disease by the Ayurvedic Regimen," Scholars Journal of Applied Medical Sciences (SJAMS), pp. 702-705, (2014):702-705.

[5] H. Rotti, R. Raval, A. S., R. Bellampalli, B. S. and e. a. Bharadwaj R, et al. "Determinants of Prakriti, the Human Constitution Types of Indian Traditional Medicine and Its Correlation with Contemporary Science." Journal of Ayurveda and Integrative Medicine 5, no. 3 (2014): 167-175. doi:10.4103/0975-9476.140478.

[6] Sharoni Narang, Saumya PSK, Omkar Batwal, and Mrunal Khandagale. "Ayurveda based Disease Diagnosis using Machine Learning." Inetnational Research Journal of Engineering and Technology (2018):3704-3707.

[7] Dunlap, Corina, Douglas Hanes, Charles Elder, Carolyn Nygaard, and Heather Zwickey. "Reliability of Self-Reported Constitutional Questionnaires in Ayurveda Diagnosis." Journal of Ayurveda and Integrative Medicine 8, no. 4 (October 2017): 257-262. doi:10.1016/j.jaim.2017.04.011.

[8] Kshirsagar, Manisha, and Ana Cristina Magno., Ayurveda: a quick reference handbook, Twin Lake, USA: Lotus Press, (2011).

[9] Usha, L., and L. Vasant. "Ayurvedic cooking for self-healing." Motilal Banarsidass Publisher, Delhi, India (2005).

[10] Prasher, Bhavana, Sapna Negi, Shilpi Aggarwal, Amit K Mandal, Tav P Sethi, Shailaja R Deshmukh, Sudha G Purohit, et al. "Whole Genome Expression and Biochemical Correlates of Extreme Constitutional Types Defined in Ayurveda." Journal of Translational Medicine 6, no. 1 (2008): 48. doi:10.1186/1479-5876-6-48.

[11] Jyothy, Kothanath Bhaskaran, and Pansi Siddhali. "Clinical Assessment of Prakriti-A Pilot Study," Journal of Research in Traditional Medicine, vol. 3, no. 6 (2017): 167-171.

[12] Bhalerao, Supriya, and Kishor Patwardhan. "Prakriti-Based Research: Good Reporting Practices." Journal of Ayurveda and Integrative Medicine 7, no. 1 (March 2016): 69-72. doi:10.1016/j.jaim.2015.08.002.

[13] Fenglin, Liu. "Female Objects and Feminist Consciousness for the Purpose to Awake Readers' Awareness: A Comparative Analysis between Angela Carter's The Bloody Chamber and Anne Sexton's Transformations." Emerging Science Journal 4, no. 1 (February 1, 2020): 25-36. doi:10.28991/esj-2020-01207.

[14] The Editors of Encyclopaedia Britannica, Unani medicine, "Mizaj" Arabian medicine, Islamic medicine, Unani Tibb. Available online: https://britannica.com/science/Unani-medicine\#ref1167451. (accessed on October 2020)

[15] Rafatullah, S., and S. Alqasoumi. "Unani Medicine: An Integral Part of Health Care System in Indian Subcontinent." European Journal of Integrative Medicine 1 (November 2008): 39-40. doi:10.1016/j.eujim.2008.08.076. 
[16] Ahmer, S. M., Ferasat Ali, Abu Waris Jamil, Hafiz Iqtidar Ahmad, and S. Javed Ali. "Mizaj: Theory of Greko-Arabic Medicine for Health and." Asian Journal of Complementary and Alternative Medicine 1 (2015):1-9.

[17] Hakim Sayed, I. A., Introduction to Al-umur Al-Tabiyah, Paharganj: Saini Printers, (1980).

[18] Naaz, Farah, Adnan Mastan, Mohd Abid, and Noman Khan. "Clinical Evaluation of Mizaj (Temperament) of the subjects of pelvic inflammatory disease." vol. 5, no. 8, (2016): 713-28.

[19] Akhtari, Marjan, Reihaneh Moeini, Morteza Mojahedi, and Narjes Gorji. "Assessment the Studies on the Concept of Mizaj (temperament) in Persian Medicine.” Journal of Complementary and Integrative Medicine 17, no. 3 (September 23, 2020). doi:10.1515/jcim-2018-0122.

[20] Mojahedi, Morteza, Mohsen Naseri, Reza Majdzadeh, Mansoor Keshavarz, Mohammad Ebadini, Esmaeil Nazem, and Mohsen Saberi Isfeedvajani. "Reliability and Validity Assessment of Mizaj Questionnaire: A Novel Self-Report Scale in Iranian Traditional Medicine.” Iranian Red Crescent Medical Journal 16, no. 3 (March 5, 2014). doi:10.5812/ircmj.15924.

[21] Mozaffarpur, Seyyed Ali, Morteza Mojahedi, Roshnak Saghebi, Abbas Alipour, and Hoda Shirafkan. "The Relationship between Mizaj and Its Indices in Persian Medicine." Advances in Integrative Medicine 6 (May 2019): S81. doi:10.1016/j.aimed.2019.03.233.

[22] Roshandel, Hamid Reza Sheikh, Fateme Ghadimi, and Romina Sheikh Roshandel. "Developing and standardization of a structured questionnaire to determine the temperament (Mizaj) of individuals." Greek, (2016).

[23] Bhushan, Patwardhan, Joshi Kalpana, and Chopra Arvind. "Classification of Human Population Based on HLA Gene Polymorphism and the Concept of Prakriti in Ayurveda." The Journal of Alternative and Complementary Medicine 11, no. 2 (April 2005): 349-353. doi:10.1089/acm.2005.11.349.

[24] Rotti, Harish, Kanive Parashiva Guruprasad, Jayakrishna Nayak, Shama Prasada Kabekkodu, Harpreet Kukreja, Sandeep Mallya, Jyothi Nayak et al., "Immunophenotyping of Normal Individuals Classified on the Basis of Human Dosha Prakriti." Journal of Ayurveda and Integrative Medicine 5, no. 1 (2014): 43-49. doi:10.4103/0975-9476.128857.

[25] Venkataraghavan, S., T. P. Sunderesan, V. Rajagopalan, and Kanchana Srinivasn. "Constitutional study of cancer patients-its prognostic and therapeutic scope." Ancient science of life 7, no. 2 (1987): 110-115.

[26] Joob, Beuy, and Viroj Wiwanitkit. "Aerobic isotonic exercise and Prameha (diabetes mellitus) as per Prakriti." An International Quaterly Journal Research in Ayurveda 33, no. 2 (2012):317. doi: 10.4103/0974-8520.105262.

[27] Nair, Pratibha P., Parvathy G. Nair, and K.M. Pratap Shankar. "An Ayurvedic Personalized Prophylactic Protocol in COVID19.” Journal of Ayurveda and Integrative Medicine (September 2020). doi:10.1016/j.jaim.2020.08.004.

[28] Kukade, Snehal V., Prashant S. Bhokardankar, Namrata Chauragade, and Bhushan Mhaiskar. "An Ayurvedic Approach of Covid-19." Journal of Critical Reviews 7, no. 10 (2020): 579-581.

[29] Neman, Kiran Anant, and Sarika Chopde. "Review of Entities in Covid-19 and its Relevance with Rachana Sharir," World Journal of Pharmaceutical REsearch, (2020):713-719.

[30] Setooni, Mahnaz, Mohsen Razeghi, Amir Mohammad Jaladat, and Ali Soleimani. "The comparison of genetic factors influences on physical activity and health between classical medicine and Iranian traditional medicine." Iranian journal of medical sciences 41, no. 3 Suppl (2016): S61.

[31] Khan, Mohammad Saad Ahmad, T. Latafat, and M. M. H. Siddiqui. "Nutrition and Immunity in the Light of Unani Medicine." Journal of Integrated Community Health 9, no. 1 (2020): 35-38.

[32] Carden, Craig P., and Ian R. Judson. "Humors of tumors: potential for interaction between cancer type and treating oncologist's personality?." Journal of Clinical Oncology 26, no. 9 (2008): 1566-1567. doi:10.1200/jco.2007.15.6711.

[33] Siavash, Mansour, Reza Ilkhani, Zahra Aghanouri, Morteza Mojahedi, Ali Montazeri, and Fatemeh Tabatabaei. "Comparing Mizaj (temperament) in Type 1 Diabetes Mellitus and Healthy Controls: A Case-control Study.” Journal of Research in Medical Sciences 24, no. 1 (2019): 58. doi:10.4103/jrms.jrms_980_18.

[34] Baig, Zarreen, Mohd Monis, and Sadique Ali. "A scientific study on Human Temperament (Mizaj) and Diabetes," International Journal of Research and Analytical Reviews, (2018):401-404.

[35] Nikhat, Sadia, and Mohammad Fazil. "Overview of Covid-19; Its Prevention and Management in the Light of Unani Medicine." Science of the Total Environment 728 (August 2020): 138859. doi:10.1016/j.scitotenv.2020.138859.

[36] Khan, Asim Ali, Fouzia Bashir, and Jamal Akhtar. "TIRYAQ E ARBA: A Classical Unani Formulation to Boost Immunity." Journal of Drug Delivery and Therapeutics 10, no. 4-s (August 15, 2020): 259-263. doi:10.22270/jddt.v10i4-s.4312.

[37] Kaur, Ramandeep, Manu Chopra, Nidhi Garg, and Hardeep S Ryait. "Role of Pulse Diagnosis: A Review." International Conference on Computing, Communication \& Automation (May 2015). doi:10.1109/ccaa.2015.7148391. 
[38] Navghare, Sonali, and Preeti Bajaj. "Detection of Prakriti of Person using Arterial Pulse Detection System with Linear Vector Quantization Method." International Journal of Computer Science and Information Security 14, no. 10 (2016): 636-641.

[39] Khajuria, Ritika, Tapsy Sharma, Ruchi Gupta, and Vasundhra Parihar. "Diagnostic aid in Ayurveda-Nadi Pariksha." Journal of Ayurveda and Integrated Medical Sciences (ISSN 2456-3110) 4, no. 6 (2020): 75-81.

[40] Bandara, R.I.S., Shageesha Prabagaran, S.A.K.G Perera, M.N Rumana Banu, and K.A.D.C.P Kahandawaarachchi. "Wedaduru -An Intelligent Ayurvedic Disease Screening and Remedy Analysis Solution.” 2019 International Conference on Advancements in Computing (ICAC) (December 2019). doi:10.1109/icac49085.2019.9103410.

[41] Shalini, T. V. "Exploring the Correlation between Body Constitution of an Individual as Per Ayurveda and Gut Microbiome Inhealthy, Multi Ethnic Urban Population In Bangalore, India." Journal of Evolutionary Medicine (2020): 18-18.

[42] Stranieri, Andrew, Kerryn Butler-Henderson, Tony Sahama, Pathirage Kamal Perera, Jonas Lima Da Silva, Danwin Pelonio, Sai Suman Manjunath, and Dharini Raghavachar. "A Visual Grid to Digitally Record an Ayurvedic Prakriti Assessment; a First Step toward Integrated Electronic Health Records." Journal of Traditional and Complementary Medicine 7, no. 2 (April 2017): 264-268. doi:10.1016/j.jtcme.2016.06.005.

[43] Tiwari, Pradeep, Rintu Kutum, Tavpritesh Sethi, Ankita Shrivastava, Bhushan Girase, Shilpi Aggarwal, Rutuja Patil, et al. "Recapitulation of Ayurveda Constitution Types by Machine Learning of Phenotypic Traits." Edited by Gyaneshwer Chaubey. PLOS ONE 12, no. 10 (October 5, 2017): e0185380. doi:10.1371/journal.pone.0185380.

[44] Madaan, Vishu, and Anjali Goyal. "Predicting Ayurveda-Based Constituent Balancing in Human Body Using Machine Learning Methods.” IEEE Access 8 (2020): 65060-65070. doi:10.1109/access.2020.2985717.

[45] Junaid Farooque, Murtaza M., Mohammed Aref, Mohammed Imran Khan, and Shareque Mohammed. "Data Mining Application in Classification Scheme of Human Subjects According to Ayurvedic Prakruti - Temperament." Indian Journal of Science and Technology 9, no. 13 (April 18, 2016). doi:10.17485/ijst/2016/v9i13/84658.

[46] Madaan, Vishu, and Anjali Gayal. “An Adaptive Neuro Fuzzy Inference System for Predicting Ayurvedic Dosha.” 2019 4th International Conference on Information Systems and Computer Networks (ISCON) (November 2019). doi:10.1109/iscon47742.2019.9036168.

[47] Becerro, Francisco Bautista. "Phraseological Variations in Medical-Pharmaceutical Terminology and Its Applications for English and German into Spanish Translations.” SciMedicine Journal 2, no. 1 (March 1, 2020): 22-29. doi:10.28991/scimedj2020-0201-4.

[48] Amin, Hetal, and Rohit Sharma. "Biochemical and Anthropometric Profiles of Different Prakriti (Ayurvedic Constitution) Patients of Non-Insulin Dependent Diabetes Mellitus." Journal of Obesity and Metabolic Research 2, no. 2 (2015): 120. doi:10.4103/2347-9906.156533.

[49] C, Pallavi, Sivakumar G, Krishna Malagi, Anoop Shastry, Shivaprakash G, and Vineetha Nayak. "A Comparative Study of Anthropometric and Body Composition Analysis Variables in Different Human Constitution Types of Indian Traditional Medicine.” National Journal of Physiology, Pharmacy and Pharmacology (2018): 1. doi:10.5455/njppp.2018.8.0309422032018.

[50] Murtaza, Syed Tariq, Farkhunda Jabin, and Mohammad Imran. "A Comparative Study of Somatotypes in Different Mizaj-eInsani." Hamdard Medicus 55, no. 3 (2012): 5-11.

[51] Mulla, G., Jalis, A. , Qureshi, F., Ghawte, S., Joshi, K. and Sha, T. "The Mizaj (Temperament) Patterns Versus Somatotypes concordance or Coincidence," Hippocratic Journal of Unani Medicine, vol. 12, no. 1, (2017):47-56.

[52] Nasir, Mohd. "Determination of Temperament with the Help of Hair Thickness and Colour." International Journal of Traditional Medicine and Applications 1, no. 1 (March 19, 2019): 18-21. doi:10.18689/ijtma-1000104.

[53] Afrough, S. and Junaid Farooque, M. M., "Integrating the process of determining Mizaj (temperament) in an hospital management System," Allana Management Journal of Research, vol. 2, no. 2, (2012).

[54] Naghizadeh, Ayeh, Donya Hamzeheian, Shaghayegh Akbari, Hossein Rezaeizadeh, Mahdi Alizadeh Vaghasloo, Mehdi Mirzaie, Mehrdad Karimi, and Mohieddin Jafari. "Revisiting Temperaments with a Fine-Tuned Categorization Using Iranian Traditional Medicine General Ontology” (November 3, 2019). doi:10.20944/preprints201911.0024.v1.

[55] Farooque, Murtaza M. Junaid, Sayyed Abidurrahman, and Farhana Sarkhawas. "Identification of Mizaj (Temprament) Based on Tibbi Fundamentals using Classification as Tool." in National Conference on Data Minning, Pune, India (2011): 94-97.

[56] Bandgar, B. M., A. D. More, and Binod Kumar. "Analysis of Temperament (Mizaj) by Using Different Data Mining Techniques," International Journal of Data Warehousing and Mining, vol. 3, no. 2, (2013): 79-81.

[57] Rezaei, Inanlou Roya, Gharehchopogh Farhad Soleimanian, and Morteza Mojahedi. "A model for temperament (Mizaj) recognition based on fuzzy decision tree in traditional Persian medicine." vol. 9, no. 3 (2018): 227-237. 
[58] Mulla, G., Ghawte, S. A., Ajmal. K. , "Mizaj and Prakruti - The twin Temperaments forming the foundation Pillars of Unani and Ayurveda Systems of Alternative Medicine" at "RAJAYUCON 2013" International Conference on "Ayurveda and Complementary System of Medicines" organized by Mission Ayurveda Rajkot in collaboration with Maharashtra University of Health Sciences, Nashik, on 23rd and 24th February, Rajkot, Gujrat, India (2013).

[59] Gazala Mulla, M. M., and H. S. Acharya. "ANN based Dual convertor model to get Ayurvedic Prakruiti from fuzzy Unani scores and Unani Mizaj from Fuzzy Ayurvedic scores," in National Confence on data Minning, Pune, India, (2013):67-70.

[60] Rolfe, Randy. The Four Temperaments: A Rediscovery of the Ancient Way of Understanding Character and Health. Marlowe \& Company, (2002).

[61] Endo, Jiro, and Teruko Nakamura. "Comparative studies of the tridosha theory in Ayurveda and the theory of the four deranged elements in Buddhist medicine." Kagakushi kenkyu; Journal of the history of science, Japan 34, no. 193 (1995): 1-9.

[62] Ahmed, Sayed I. "Introduction to Al-Umur-Al-Tabi’Yah." A \& U Tibbi College, Ministry of Health and Family Welfare, New Delhi, Govt. of India, New Delhi (2009): 109-113.

[63] Naisal, S. A., and K. Reji Kumar. "A Mathematical Modeling of Ayurveda Doshas: Application of Fuzzy Soft Topology." International Journal of Pure and Applied Mathematics 106, no. 8 (2016): 33-43.

[64] Smarandache, Florentin. Neutropsychic Personality: A mathematical approach to psychology. Infinite Study, (2018). 